\title{
The Effect of Link N on Mesenchymal Stem Cell Under IL-1 $\beta$ Stimulation
}

\author{
Mu-Chen Yang ${ }^{1}$, Ding-Han Wang ${ }^{1}$, Wun-Eng Hsu², Ming-Lun Hsu ${ }^{1 *}$ \\ 1. School of Dentistry, National Yang-Ming University, No.155, Sec.2, Linong Street, Taipei, 112, Taiwan (ROC) \\ 2. Department of Stomatology, Taipei Veterans General Hospital, No.201, Sec. 2, Shipai Rd., Taipei, 112, Taiwan \\ (ROC) \\ *E-mail: mlhsu@ym.edu.tw
}

\begin{abstract}
Objective: Temporomandibular joint (TMJ) arthritis can be induced by several inflammatory cytokines that may affect extracellular matrix (ECM) component expression. Link-N is exfoliated from Link protein (LP) which is one of the ECM components. It possesses ability to stimulate synthesis of ECM component. However, information regarding the potential of Link-N to modulate inflammatory process remains lacking.
\end{abstract}

Methods: Mesenchymal stem cells (MSCs) derived from oral adipose tissues were isolated from dental operation under regulation of IRB, and were stained by the early stage stem cell markers (OCT4, NANOG, REX1, and SOX2). MSCs were under IL-1 $\beta(1 \mathrm{ng} / \mathrm{ml})$ or Link-N $(1 \mu \mathrm{g} / \mathrm{ml})$ stimulation at 24 hours and 96 hours. Cell supernatant were collected then concentration quantification of cytokines was performed by Luminex multiplex assays.

Results: MSCs showed the early stage stem cell markers. IP-10 and IL-6 increased significantly under IL$1 \beta$ stimulation, but Link-N did not. The protection marker, IL-4, IL-13 elevated during Link-N treatment compared with only IL- $1 \beta$ stimulation at 24,96 hours. The chondrogenesis regulator, TGF- $\beta$, increased significantly compared with only IL- $1 \beta$ stimulation at 96 hours.

Conclusion: During inflammation, Link-N can inhibit inflammatory response. On the other hand, it can enhance protection marker and chondrogenesis regulator expression. Link $\mathrm{N}$ may provide additional effect to assist joint repair.

Keywords: link protein $\mathrm{N}$ terminal peptide, mesenchymal stem cells, temporomandibular joint arthritis

\section{Introduction}

Temporomandibular joint (TMJ) is unique joint of body. It consists of fibrocartilage tissue which can adaptive to compressive load. ${ }^{1}$ It distributes in TMJ disc and the surface of condyle and glenoid fossa. The fibrocartilage tissue composes of extracellular matrix (ECM) that typically provides a structural and biochemical support to the surrounding cells. ${ }^{2}$ One of composition in ECM call link protein (LP), it can be a stabilizer to keep the interaction between aggrecan and hyaluronic acid (HA). ${ }^{3}$ In articular cartilage, LP belongs to small glycoprotein and presents three isoforms which derived from same structural gene. ${ }^{4}$ LP1 and LP2 have same protein core but different glycosylated forms. However, LP3 is formed from LP1 and LP2 by proteolytic cleavage between His16- Ile17. The metalloproteinase stromelysin is major role to cleavage the $\mathrm{N}$ - terminal of link protein than exfoliate a small peptide (16 amino acids) which is known as Link $\mathrm{N}^{5,6}$.

TMJ arthritis is one of the classification of TMJ disorders. $^{7}$ During arthritis, there are many pro- inflammatory cytokines will be produced and further attack the joint. For instance, interleukin-1 beta (IL-1 $\beta$ ) plays critical role in the pathogenesis of osteoarthritis. IL$1 \beta$ has ability to decrease ECM compounds production and increase matrix metalloproteinases (MMPs) family expression..$^{8,9}$ In previous studies, there are many ways to reduce joint inflammatory condition, such as $\mathrm{HA}$ and corticosteroids. ${ }^{10,11}$ However, Link $\mathrm{N}$ can be another material for reducing inflammation. Because it has been used in intervertebral disc (IVD) degeneration, both in vivo and in vitro studies. ${ }^{12,13}$ During IVD degeneration, Link $\mathrm{N}$ can stimulate aggrecan and down regulate proteinase gene expression. In addition, Link $\mathrm{N}$ can through the Smad1/5 pathway to enhance ECM expression. Hence, Link $\mathrm{N}$ is indicated that possesses growth factor-like property. ${ }^{14}$

Recently, more and more studies try to use mesenchymal stem cells (MSCs) for further effective treatment, including to enhance TMJ repair. ${ }^{15,}{ }^{16}$ MSCs are multipotent stem cells. ${ }^{17}$ When MSCs culture with other factors can bring others benefits to repair process. Some of studies have demonstrated that MSCs co-culture with 
Link $\mathrm{N}$ under chondrogenesis condition can enhance MSCs toward chondrogenic differentiation. ${ }^{13}$ Link $\mathrm{N}$ could be a potential material for joint repair. According to previous studies, the structure of IVD is similar to TMJ which consist of fibrocartilage tissue. ${ }^{18}$ Thus, this study is trying to use Link $\mathrm{N}$ that have already utilized in IVD treatment then change to TMJ and further evaluate its efficacy. In addition, there are few studies discuss about the respond of MSCs were treated with Link N under inflammatory condition. The purpose of this research was to evaluate the respond of Link N on MSCs under IL-1 $\beta$ stimulation.

\section{Methods}

\section{Cell isolation and culture}

MSCs were isolated from oral adipose tissue which obtained from clinical surgery and certified by the Institutional Review Board of Tri- Service General Hospital (Taipei, Taiwan). MSCs isolation was performed according to the previously described protocol. ${ }^{19}$ In brief, the tissue was transferred into Dulbecco's modified Eagle's medium (DMEM; Gibco, Carlsbad, CA, USA) containing $0.1 \%$ collagenase (Sigma, St. Louis, MO, USA). After 24 hours' incubation, the tissue was transferred into DMEM; 10 per cent fetal bovine serum (FBS; Gibco, Carlsbad, CA, USA) for 24 hours. After centrifugation at $500 \mathrm{~g}$ for 5 minutes, all cell was expanded in keratinocyte serum-free medium (K-SFM; Gibco, Carlsbad, CA, USA); 5 per cent FBS, antioxidants Nacetyl-cysteine and L-ascorbic acid-2-phosphate (Sigma, St. Louis, MO, USA) in a humidified atmosphere of 5 per cent $\mathrm{CO} 2$ in air at $37^{\circ} \mathrm{C}$.

\section{Stemness identified by immunofluorescence staining}

To identify the expression of Oct 4 , Nanog and Sox-2, MSCs were fixed with 4 per cent paraformaldehyde for 10 min. Then, wash by 0.05 per cent tween in phosphate buffered saline (PBST) 2 times and each time for 2 minutes. Cells were permeabilized in 0.2 per cent Triton X-100 for 10 minutes followed by washing with PBST 3 times and each time for 5 minutes. Following blocking for 20 min with serum at room temperature. Cells were incubated overnight at $4{ }^{\circ} \mathrm{C}$ in primary antibody (antiOct4; anti-Sox-2; anti-Nanog). Cells were washed in PBST 3 times and each time for 5 minutes followed by incubation with the secondary antibodies for 30 minutes at room temperature. Nuclei are stained with DAPI.

\section{Peptide Synthesis}

Link $\mathrm{N}$ were synthesized by Mission Biotech (Taipei, Taiwan). There were 16 amino acids (DHLSDNYTLDHDRAIH) which is consensus sequence for human link protein peptide. Released peptides were purified to $>95 \%$ by high performance liquid chromatography, characterized by electrospray ionization mass spectroscopy, and lyophilized to dryness. They were stored at $-20{ }^{\circ} \mathrm{C}$ before use.

\section{Luminex assay}

Cells were seeded into $25 \mathrm{~cm} 2$ flask. After cells attached completely and density up to 60 per cent, the cells were prepared to treating different conditions. Each flask for one condition. There were divided into four groups and at two time points, 24 and 96 hours. MSCs were treated Link $\mathrm{N}(1 \mu \mathrm{g} / \mathrm{ml})$ only and under IL- $1 \beta(1 \mathrm{ng} / \mathrm{ml})$ stimulation with or without Link $\mathrm{N}(1 \mu \mathrm{g} / \mathrm{ml})$. Untreated MSCs was used as control. Cell supernatant were collected then concentration quantification of cytokines with a highsensitivity human cytokine kit for simultaneous multianalyte detection with Luminex technology (Milliplex®, Millipore, Darmstadt, Germany), according to the manufacturer's instructions.

\section{Statistical analysis}

Statistical analysis was performed with SPSS version 16 software. All data are presented as the mean \pm standard deviation (SD). Using one way Anova with post-hoc Bonferroni test to analyze the data. P values less than 0.05 were considered as significant.

\section{Results}

In order to demonstrate MSCs stemness, the cell were identified by immunofluorescence staining. All the cells had ability to express OCT, NANOG, SOX2 and REX1 which were the early stages of stem cell markers (Figure 1). After identify stemness, MSCs were divided into four groups. First was non-treated group, known as control. Second and third were treated with only IL-1 $\beta$ and Link N respectively. Forth was treated with IL-1 $\beta$ and Link N. These forth groups were separated to two-time point, 24 and 96 hours. To mimic inflammatory condition, MSCs were exposed to $1 \mathrm{ng} / \mathrm{ml} \mathrm{IL-1 \beta}$ for 24 hours. The inflammatory marker IL-6 and IP-10 expressed significantly $(\mathrm{p}<0.001 ; \mathrm{p}<0.001)$. While MSCs were only exposed to $1 \mu \mathrm{g} / \mathrm{ml}$ Link $\mathrm{N}$ did not induced IL-6 and IP-10 expression. The results were showed similar to control. Although the expression of IL-6 and IP-10 treated together with Link $N$ and IL-1 $\beta$ were higher than only Link $N$ group $(p<0.001 ; p<0.001)$, but decreased significantly compared with only IL- $1 \beta$ group $(\mathrm{p}<0.001$; $\mathrm{p}<0.001$ ) (Figure 2).

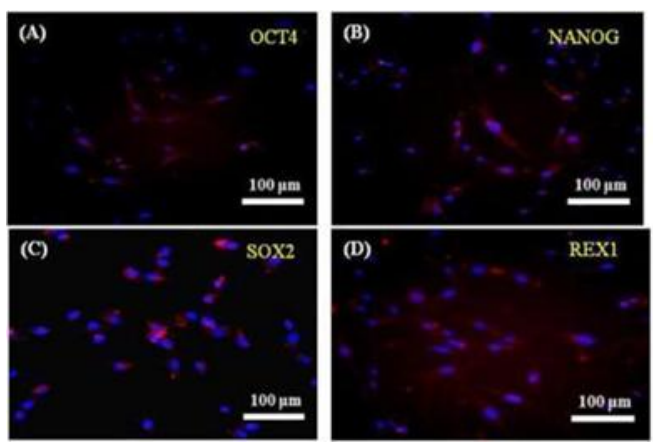

Figure 1. MSCs derived from oral adipose tissues were isolated from dental operation following IRB. Before doing the experiment, MSCs stemness were identified by immunofluorescence staining. MSCs express the early stage stem cell markers 
(A) OCT4, (B) NANOG, (C) SOX2 and (D) REX1. Scale bar $=100 \mu \mathrm{m}$
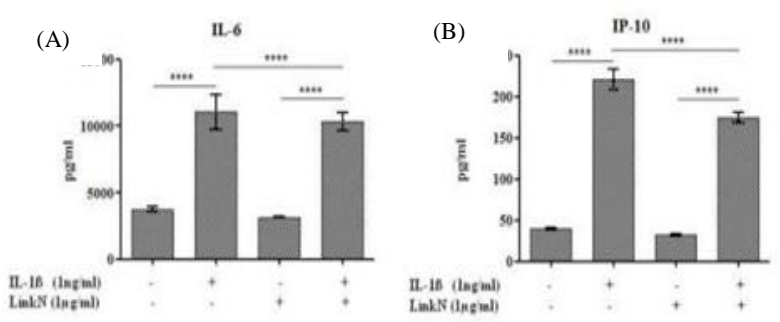

Figure 2. To confirm inflammatory condition, IL-6 and IP-

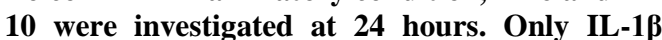
stimulation showed (A) IL-6 and (B) IP-10 increased significantly compared with control. Only Link $N$ treatment did not show any difference from control. After IL-1 $\beta$ and Link N co-stimulation, IL-6 and IP-10 decreased significantly compared with only IL-1及 stimulation. $* * * * \mathrm{p}<0.001$

To evaluate the protected marker expression at 24 and 96 hours, the expression of IL- 4 and IL-13 were investigated. At 24 hours, IL-4 increased significantly under individual IL-1 $\beta \quad(p<0.05)$ and Link $N$ stimulation $(p<0.005)$ compared with control. While MSCs were treated together with Link $\mathrm{N}$ and IL-1 $\beta$, it showed obviously raising compared with only IL-1 $\beta(\mathrm{p}<0.01)$ and only Link $N$ $(p<0.05)$ groups (Figure 3A). Although IL-13 did not show any significant different, but there were increasing trend under individual IL-1 $\beta$ and Link $\mathrm{N}$ stimulation compared with control. As well as MSCs were treated together with Link $\mathrm{N}$ under IL-1 $\beta$ stimulation, it also showed increasing trend compared with others groups (Figure 3B). At 96 hours, the expression of IL-4 and IL13 in control group were higher than others groups. There were obviously difference between control and only IL-1 $\beta$ group $(\mathrm{p}<0.05 ; \mathrm{p}<0.05)$. These markers were raised up with or without IL-1 $\beta$ under Link $N$ treatment (Figure 3CD).
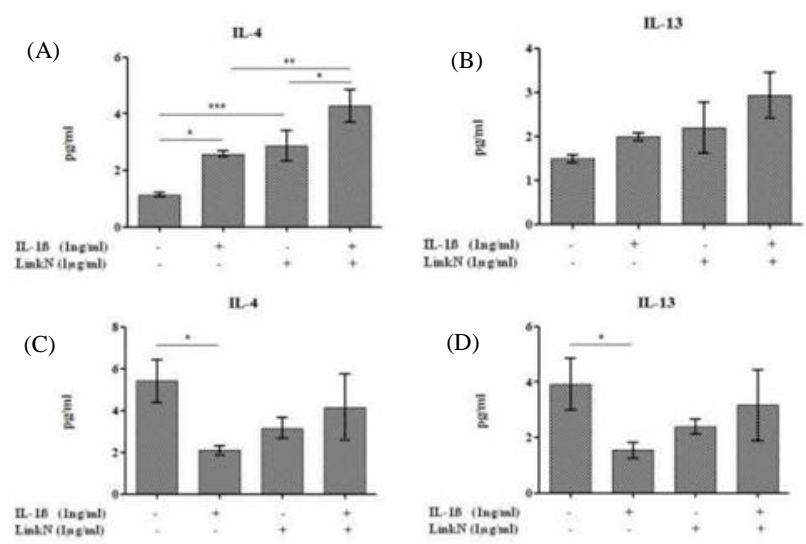

Figure 3. To evaluate the protected marker expression at 24 and 96 hours, the expression of IL-4 and IL13 were investigated. At 24 hours, (A) IL-4 were increased significantly and (B) IL-13 showed increasing trend after IL- 1 $\beta$, Link $N$ individual treatment and co-stimulation. At 96 hours, the expression of (C) IL-4 and (D) IL-13 were higher than others groups. There were increasing trend under Link $N$ treatment, especially IL-1 $\beta$ and Link $N \quad$ co-stimulation. $* p<0.05, * * p<0.01$, $* * * \mathbf{p}<0.005, * * * * \mathbf{p}<0.001$

To evaluate the chondrogensis markers, TGF- $\beta 1$, TGF- $\beta 2$ and TGF- $\beta 3$ were investigated at 96 hours. After only IL$1 \beta$ stimulation, the expression of TGF- $\beta 1$ and TGF- $\beta 3$ decreased significantly compared with control $(p<0.001$; $\mathrm{p}<0.05)$ and co- stimulation group $(\mathrm{p}<0.001 ; \mathrm{p}<0.01)$ (Figure 4A, C). The expression of TGF- $\beta 3$ treated together with Link $N$ and IL-1 $\beta$ showed increasing trend than others groups (Figure 4C). The expression of TGF- $\beta 2$ showed no difference between only IL-1 $\beta$ and Link N group, but it presented significantly raised up after IL-1 $\beta$ and Link $N$ co-stimulation compared with only IL-1 $\beta$ $(\mathrm{p}<0.001)$ and Link $\mathrm{N}$ groups $(\mathrm{p}<0.005)$ (Figure 4B). Only Link $\mathrm{N}$ treatment showed similar result to control (Figure 4).
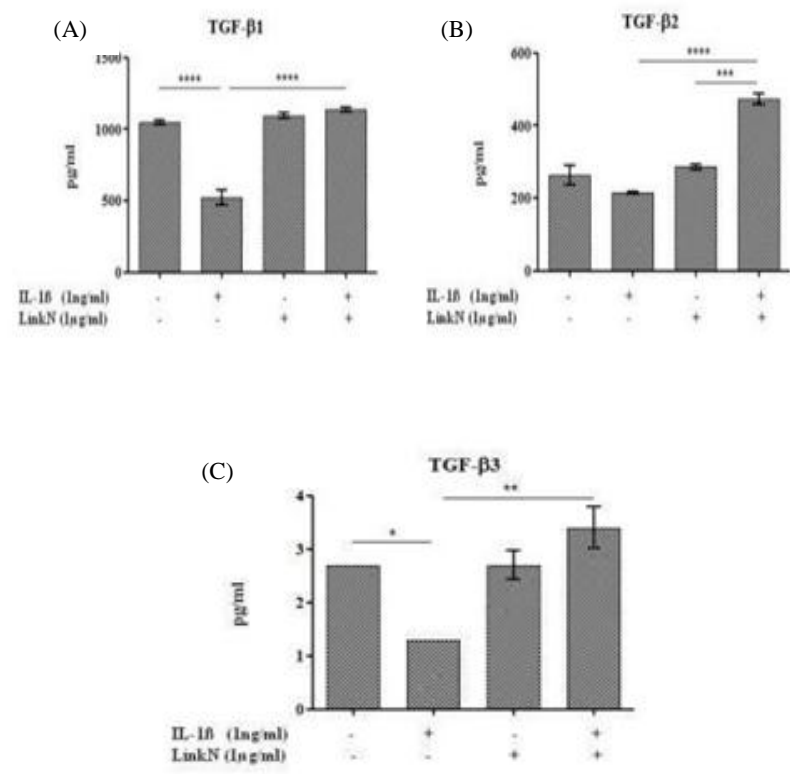

Figure 4. To evaluate the chondrogensis markers, TGF- $\beta 1$, TGF- $\beta 2$ and TGF- $\beta 3$ were investigated at 96 hours. (A)Only IL-1 $\beta$ stimulation showed TGF- $\beta 1$ decreased significantly than others groups. (B) After IL- $1 \beta$ and Link $N$ costimulation showed significantly raised up.

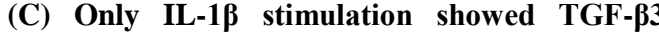
decreased significantly than others groups. And it presented increasing trend, after IL-1 $\beta$ and Link $\mathbf{N}$ co-stimulation. $* \mathbf{p}<0.05, \quad * * \mathrm{p}<0.01$, $* * * \mathbf{p}<0.005, * * * * \mathbf{p}<0.001$

\section{Discussion}

In present study, Link $\mathrm{N}$ did not induce the expression of IL-6 and IP-10 at 24 hours. However, Link N can inhibit inflammatory responder under IL- $1 \beta$ stimulation. Link $N$ not only induce protective marker expression, but also enhance these marker expressions under IL-1 $\beta$ stimulation 
at 24 hours. After 96 hours' treatment, Link N showed increasing trend under IL-1 $\beta$ stimulation. Simultaneously, there was slight increase in chondrogenesis regulator markers, but this was not significant. In contrast, Link N treat with IL-1 $\beta$ led to a significant increase compared with only IL-1 $\beta$ stimulation. Although only Link $N$ treatment can change environment to a certain extent, but not much than under IL-1 $\beta$ stimulation. Thus, Link $\mathrm{N}$ may have additional effect with another factor stimulation.

There are some of studies have demonstrated Link $\mathrm{N}$ with other factors can provide additional effect for obviously reduces inflammatory condition or enhances differentiation potential of MSCs. When Link N cultures with MSCs in chondrogenesis medium, it enhances some of marker relative to transcription factor of chondrogenesis increasing. In contrast, Link $\mathrm{N}$ cultures with MSCs in serum- free medium, it cannot induce any

Proteoglycan production13. In addition, some of inflammatory cytokines levels were downregulated after Link $\mathrm{N}$ treatment under IL-1 $\beta$ stimulation which results are similar to our study. Although MMP3 showed upregulated which were different from another study, but the consequences may attribute to different cells type and culture days. ${ }^{12,20}$ Therefore, these can provide that Link $\mathrm{N}$ could be a promotor not an initiator. Il-6 plays an important role in inflammatory respond and identified inflammatory disease. ${ }^{21,22}$ During joint arthritis, IL-1 $\beta$ has already been demonstrated through NF-KB or MAPK pathway can induce Il-6 producing. IL-1 $\beta$ also induce proteinase and inhibit ECM expression ${ }^{23}$. In addition, IP10 (IFN- $\gamma$-inducible protein of $10 \mathrm{kDa}$ ) is a member of the CXC chemokine family which is secreted by different cell type such as monocytes, neutrophils, et al. Not only IFN- $\gamma$ can induce IP-10 expression, but also IL-1 $\beta$ is one of the induction factor. ${ }^{24}$ Thus, IL- $1 \beta$ can mimic inflammatory condition and have been used in widely studies. Il-4 and Il-13 have anti-inflammation and chondroprotective potential in joint arthritis. These markers can stimulate cell to produce proteoglycan, proliferation and inhibit cell apoptosis. ${ }^{23,25,26}$. On the other hand, TGF family play important role in chondrogenic differentiation and also stimulate matrix synthesis. ${ }^{27,}{ }^{28}$ Different isoforms show different effect, for example TGF- $\beta 1$ induced mesenchymal cell condensation and TGF- $\beta 3$ increased mesenchymal cell proliferation. ${ }^{29}$ Although TGF- $\beta 1$ and TGF- $\beta 3$ showed similar result in present study, but if confirm by another experiment such as immunofluorescence staining in the future. It may provide more evidences to realize the property of cells after Link $\mathrm{N}$ treatment. Base on the results of this study, Link $\mathrm{N}$ may enhance potential of recovery during inflammatory condition.

Link $\mathrm{N}$ have been mentioned it could be a growth factor and guide a disc- like or a cartilage-like matrix formation13. Up to now, there were lack studies try to use Link $\mathrm{N}$ in animal to clarify the effect to TMJ. Therefore, the application of Link $\mathrm{N}$ in vivo is necessary to be clarified first. In the future, it could be a potential material for using in TMJ disorders. In conclusion, Link $\mathrm{N}$ can inhibit inflammatory response during inflammation. On the other hand, it can enhance protection marker and chondrogenesis regulator expression. Link $\mathrm{N}$ may provide additional effect to assist joint repair.

\section{Conclusion}

During inflammation, Link-N can inhibit inflammatory response. On the other hand, it can enhance protection marker and chondrogenesis regulator expression. Link $\mathrm{N}$ may provide additional effect to assist joint repair.

\section{References}

1. Wadhwa S, Kapila S. TMJ disorders: future innovations in diagnostics and therapeutics. Journal of dental education. 2008;72(8):930-47.

2. Michel G, Tonon T, Scornet D, Cock JM, Kloareg B. The cell wall polysaccharide metabolism of the brown alga Ectocarpus siliculosus. Insights into the evolution of extracellular matrix polysaccharides in Eukaryotes. The New phytologist. 2010;188(1):82-97.

3. Han L, Grodzinsky AJ, Ortiz C. Nanomechanics of the Cartilage Extracellular Matrix. Annual review of materials research. 2011;41:133-68.

4. Wang Z, Hutton WC, Yoon ST. ISSLS Prize winner: Effect of link protein peptide on human intervertebral disc cells. Spine. 2013;38(17):1501-7.

5. Mwale F, Demers CN, Petit A, Roughley P, Poole AR, Steffen T, et al. A synthetic peptide of link protein stimulates the biosynthesis of collagens II, IX and proteoglycan by cells of the intervertebral disc. Journal of cellular biochemistry. 2003;88(6):1202-13.

6. Dean MF, Sansom P. Link peptide cartilage growth factor is degraded by membrane proteinases. The Biochemical journal. 2000;349(Pt 2):473-9.

7. Anderson GC, Gonzalez YM, Ohrbach R, Truelove EL, Sommers E, Look JO, et al. The Research Diagnostic Criteria for Temporomandibular Disorders. VI: future directions. Journal of orofacial pain. 2010;24(1):79-88.

8. Sokolove J, Lepus CM. Role of inflammation in the pathogenesis of osteoarthritis: latest findings and interpretations. Therapeutic advances in musculoskeletal disease. 2013;5(2):77-94.

9. Noh EM, Kim JS, Hur H, Park BH, Song EK, Han MK, et al. Cordycepin inhibits IL-1beta-induced MMP-1 and MMP-3 expression in rheumatoid arthritis synovial fibroblasts. Rheumatology. 2009;48(1):45-8.

10. Manfredini D, Piccotti F, Guarda-Nardini L. Hyaluronic acid in the treatment of TMJ disorders: a systematic review of the literature. Cranio : the journal of craniomandibular practice. 2010;28(3):166-76.

11. Machado E, Bonotto D, Cunali PA. Intra-articular injections with corticosteroids and sodium hyaluronate for treating temporomandibular joint disorders: a systematic review. Dental press journal of orthodontics. 2013;18(5):128-33.

12. Mwale F, Masuda K, Pichika R, Epure LM, Yoshikawa T, Hemmad A, et al. The efficacy of Link $\mathrm{N}$ as a mediator of repair in a rabbit model of intervertebral disc degeneration. Arthritis research \& therapy. 2011;13(4):R120.

13. Antoniou J, Wang HT, Alaseem AM, Haglund L, Roughley PJ, Mwale F. The effect of Link N on differentiation of human bone marrow-derived mesenchymal stem cells. Arthritis research \& therapy. 2012;14(6):R267.

14. Wang Z, Weitzmann MN, Sangadala S, Hutton WC, Yoon ST. Link protein N-terminal peptide binds to bone morphogenetic protein (BMP) type II receptor and drives matrix protein expression in rabbit intervertebral disc cells. The Journal of biological chemistry. 2013;288(39):2824353.

15. Zhang S, Yap AU, Toh WS. Stem Cells for Temporomandibular Joint Repair and Regeneration. Stem cell reviews. 2015;11(5):728-42. 
16. Maenpaa K, Ella V, Mauno J, Kellomaki M, Suuronen R, Ylikomi T, et al. Use of adipose stem cells and polylactide discs for tissue engineering of the temporomandibular joint disc. Journal of the Royal Society, Interface / the Royal Society. 2010;7(42):177-88

17. Zou JP, Huang S, Peng Y, Liu HW, Cheng B, Fu XB, et al. Mesenchymal stem cells/multipotent mesenchymal stromal cells (MSCs): potential role in healing cutaneous chronic wounds. The international journal of lower extremity wounds. 2012;11(4):244-53.

18. Adam M, Deyl Z. Degenerated annulus fibrosus of the intervertebral disc contains collagen type II. Annals of the rheumatic diseases. 1984;43(2):258-63.

19. Cherng JH CS, Fang TJ, Liu ML, Li CH, Yang SF, et al. Surgical-derived oral adipose tissue provides early stage adult stem cells. J Dent Sci. 2014;9(1):10-5

20. Gawri R, Antoniou J, Ouellet J, Awwad W, Steffen T, Roughley P, et al. Best paper NASS 2013: link-N can stimulate proteoglycan synthesis in the degenerated human intervertebral discs. European cells \& materials. 2013;26:107-19; discussion 19 .

21. Cahill CM, Rogers JT. Interleukin (IL) 1beta induction of IL-6 is mediated by a novel phosphatidylinositol 3-kinasedependent AKT/IkappaB kinase alpha pathway targeting activator protein-1. The Journal of biological chemistry. 2008;283(38):25900-12.

22. Rincon M. Interleukin-6: from an inflammatory marker to a target for inflammatory diseases. Trends in immunology. 2012;33(11):571-7

23. Wojdasiewicz P, Poniatowski LA, Szukiewicz D. The role of inflammatory and anti-inflammatory cytokines in the pathogenesis of osteoarthritis. Mediators of inflammation. 2014;2014:561459.

24. Wang S, Diao N, Lu C, Wu J, Gao Y, Chen J, et al. Evaluation of the diagnostic potential of IP-10 and IL-2 as biomarkers for the diagnosis of active and latent tuberculosis in a BCG-vaccinated population. PloS one. 2012;7(12):e51338.

25. Assirelli E, Pulsatelli L, Dolzani P, Platano D, Olivotto E Filardo G, et al. Human osteoarthritic cartilage shows reduced in vivo expression of IL-4, a chondroprotective cytokine that differentially modulates IL-1beta-stimulated production of chemokines and matrix-degrading enzymes in vitro. PloS one. 2014;9(5):e96925.

26. Relic B, Guicheux J, Mezin F, Lubberts E, Togninalli D, Garcia I, et al. Il-4 and IL-13, but not IL-10, protect human synoviocytes from apoptosis. Journal of immunology. 2001;166(4):2775-82.

27. Tuli R, Tuli S, Nandi S, Huang X, Manner PA, Hozack WJ, et al. Transforming growth factor-beta-mediated chondrogenesis of human mesenchymal progenitor cells involves $\mathrm{N}$-cadherin and mitogen-activated protein kinase and Wnt signaling cross-talk. The Journal of biological chemistry. 2003;278(42):41227-36.

28. Tew SR, Murdoch AD, Rauchenberg RP, Hardingham TE. Cellular methods in cartilage research: primary human chondrocytes in culture and chondrogenesis in human bone marrow stem cells. Methods. 2008;45(1):2-9.

29. James AW, Xu Y, Lee JK, Wang R, Longaker MT. Differential effects of TGF-beta1 and TGF-beta3 on chondrogenesis in posterofrontal cranial suture-derived mesenchymal cells in vitro. Plastic and reconstructive surgery. 2009;123(1):31-43. 